such as the Nature Conservancy and World Wildlife Fund. Each of the remaining sections begins with an overview of the section and then papers on that topic. The second part of the book consists of seven papers on the theme of "Conservation of Endangered Species." The papers cover a variety of species (e.g., tree snails, rock iguanas, New Zealand birds, Australian marsupials) and topics (e.g., ex situ propagation, amphibian decline, conservation endocrinology). Section three, "Control or Elimination of Exotic and Intensive Species" features three papers on the subjects of California grasslands, tree invasions and the use of biological controls on exotic species. The final section of the book, "Policyrelated Matters" contains four papers. Topics include the case study of the US Army and the Desert Tortoise and the challenge of biodiversity conservation within African national parks.

As is usually the case in such volumes, the papers vary substantially in their scope and quality. At one

\section{Gulls of North America, Europe, and Asia}

By Klaus Malling Olsen and Hans Larsson. $2004 \$ 55.00$ Cloth.

My reaction on opening this book was akin to the one I had when I first saw Seabirds ${ }^{1}$ - this is a giant leap forward. It is a glorious wad of text accompanied color paintings (by Larsson), wonderful range maps and a multitude of color photographs. The authors say they cover forty-three species of gull. I found there are 50 species of gull worldwide that have generally been accepted in the recent literature. Of the 43 covered in this book 37 are on the world list. The remaining species are splits made and justified by the authors. These are Thayer's, American Herring. Caspian, Vega, Heuglin's and Common Gulls. Adding these in would bring the world total to 56. Also included are three South American vagrant species that are covered by a short text and a couple of photos. This means the book covers threequarters of the world's gull species.

Each species is described in extensive detail, with a full description of all plumages at all life stages and racial variations. The accompanying illustrations support the text in these details. Additionally there are some comparison plates comparing similar species.

So this is a book of detail and it is in the detail we find the devil. Gull taxonomy is notoriously complex, poorly understood and subject to argument. I decided to examine first the Herring Gull and the newly-split American Herring Gull. Comparing the descriptions with the author's illustrations of the adult, I found it difficult to discern the majority of the "differences." I have noted similar bird-to-bird variations in single flocks of each one of these "species." I quickly realized I was concentrating on the photos and not the paintings, as I found the depictions too pale. The photos were closer to the pearl grey of my memory. There are comparison plates of large gull taxa (a good idea) where the American Herring Gull is shown as paler than an Iceland Gull. This is not an error as it is set in the middle of Glaucous extreme, Michael Hadfield and collaborators provide an overview of the over 20 years of work his lab has done on the conservation of Hawaiian tree snails of the genus Achatinella. Their work has combined markrecapture field studies, devising field exclosures to protect populations, developing protocols to maintain populations in the lab, and developing conservation priorities through the use of genetic markers. In contrast, other papers focus on a single issue or experiment. In addition, although all the papers were prepared for this book they vary in format, with only some of the papers including a summary. Nonetheless, this is a strong collection of papers, displaying the breadth of experimental conservation biology.

DAVID SEBURN

Seburn Ecological Services, 2710 Claenda Street, Ottawa, Ontario K2B 7S5 Canada

and Glaucous-winged Gulls, and not with the European Herring and Yellow-legged Gulls.

The comparison of the non-adult plumages is even more difficult. Picking your way through the myriad of details of multiple plumages for each species is time consuming and can be tedious. This is not a criticism nor a question of right and wrong, but more the part of an ongoing debate. It has prompted me to look more carefully at the local American Herring Gulls this year.

Nowhere does this taxonomic debate emerge more clearly than with Thayer's Gull. The author notes "Taxonomic status not fully clarified." Many years ago I went through three trays of study skins at the Canadian Museum of Nature in Ottawa. The first tray contained Iceland gulls. The second contained Thayer's Gulls. The problem was the third tray had birds that looked like one of these species on their left side and the other species from the right side. In addition, during my years in Nova Scotia the commonest winter bird in my backyard was the Iceland Gull and I soon realized that it was a very variable species.

Next I turned my attention to the adult Great Blackbacked Gull. This raised further questions. The text says "Legs flesh, sometimes with a grey or creamy (rarely yellow or extremely orange) tinge." (my emphasis). Legs flesh, sometimes with a grey or creamy tinge certainly fits the birds I have seen. I have found a yellow-legged bird. The next species is the Kelp, also large and black-backed. The adult's feet are yellow but could be greyish-olive or greenish. When I, carefully (you do not want to damage the fine photos), curl the photos back so I can see the two birds side by side they are very similar, separated by their feet colour. If we had a grayish-footed Kelp Gull wander north would we notice it and would I get excited at a yellow footed Black-back? Yellow legs is the classic mark for separating the Lesser Black-back Gull. 
Clearly identifying gulls is fraught with lots of pitfalls for the less than careful. Identification of vagrant gulls need to be done with vast care and all the field marks need to be examined. Likewise we should not pass off our local crowd of gulls as being the usual species; a great treasure could be hidden in the flock.

The pros and cons of gull taxonomy notwithstanding, this book is a wealth of information. The same exacting detail is given for all the species in the book, making it a treasure trove for the dedicated birder. Regardless of your opinion on the status of the species splits, there is much material for good scientific discussion and a basis for careful field observations. This all leads to the final question - why not go all the way and write Gulls of the World. After all it is only 13 more species, barring splits!

ROY JOHN

2193 Emard Crescent, Beacon Hill North, Ottawa, Ontario K1J 6K5 Canada

\section{Literature Cited}

Harrison, Peter. 1983. Seabirds: An Identification Guide. Helm Field Guides Houghton Mifflin Co., Boston, Massachusetts

\section{The Monarch Butterfly: Biology and Conservation}

By Karen S. Oberhauser and Michelle J. Solensky, Eds. 2004. Cornell University Press, New York. vii +248 pages, illus. $\$ 39.95$ US.

This book consists of a collection of scientific papers on the Monarch, divided into chapters on reproduction, migration and overwintering biology as well as some miscellaneous papers on general topics. Each of the four chapters is prefaced by a brief overview written by the editors. Karen Oberhauser is an Assistant Professor at the University of Minnesota, while Michelle Solensky is with the Department of Biology at the University of St. Thomas. The information presented includes observations from each of the three major Monarch populations worldwide (eastern and western North America and Australia).

This book contains a great deal of interesting information, presented as original scientific literature. The majority of the papers are well-written, although some are likely to be overly technical (especially in terms of the statistical analyses) for some readers. Of particular interest are the papers on citizen-based research programs, which present data collected by widespread networks of volunteers. These papers demonstrate how, with relatively modest training and logistical support, public participation can be used to enable research into wide-ranging populations which could otherwise prove difficult or impossible to monitor effectively. The overviews which introduce each of the four chap- ters help to make the information presented in the book more accessible to a broader audience (including, perhaps, some of the volunteers whose efforts are reported).

The black-and-white photographs which accompany each overview are excellent. However, the overall paucity of illustrations (other than the numerous graphs contained within the various papers) is regrettable. With such a colourful and attractive subject as the Monarch, surely it would not have been difficult to find more photographs to include in the book? Aside from their purely aesthetic value, additional photographs or drawings could have been used to enhance the text by illustrating some of the features, behaviours and methodologies described (e.g., growth and development, wing damage caused by courtship, experimental equipment design, etc.).

In short, this book presents interesting data on every major aspect of Monarch biology, with additional emphasis on the need to extend and incorporate such data into ongoing and future conservation efforts. However, the scientific format of the text may deter some readers, which is unfortunate considering the widespread public interest (as acknowledged in the book) in this familiar and beloved butterfly species.

AMY MACPHERSON

Jacques Whitford Limited, 2781 Lancaster, Ottawa, Ontario K19 1A7 Canada

\section{The Behavior and Ecology of Pacific Salmon and Trout}

By Thomas P. Quinn. 2005. American Fisheries Society in Association with the University of British Columbia Press, Vancouver, Canada. 378 pages, illus. Cloth CDN \$85.00; paper CDN \$44.95.

The vast amount of literature on the Pacific salmon is rather intimidating. Indeed, several years ago when I first began conducting research on this group of fish after leaving the Midwest, it was difficult to know where to begin. Today there is a clear starting point I would read The Behavior and Ecology of Pacific Salmon and Trout by Thomas Quinn. This book is an excellent resource for students and fisheries scientists, providing a broad overview of Pacific salmon ecology. However, this book also has broader appeal to animal ecologists and naturalists. Thomas Quinn is a prominent ecologist (Professor at the University of Washington) who has devoted his career to research on Pacific salmon. He shares his passion and experience in the first comprehensive book to focus on the ecology and behaviour of the Pacific salmon. This book is complimentary to other compilations on this group of fishes such as the Physiological Ecology of Pacific Salmon by Groot, Margolis, and Clarke.

The book is focused on the salmon and trout in the Genus Oncorhynchus. This multi-species approach is one that could easily lead to confusion. However, Quinn 